\title{
Minimally Invasive Surgery of the Forefoot: Current Concept Review
}

\author{
Bruno Magnan $^{1}$, Manuel Bondi ${ }^{2 *}$, Silvio Mezzari ${ }^{1}$, Ingrid Bonetti ${ }^{1}$, Elena Samaila $^{1}$ \\ ${ }^{1}$ Orthopaedic Department, Surgical Center “P. Confortini”, University of Verona, Verona, Italy; ${ }^{2}$ Department of Orthopaedics and \\ Traumatology, Carlo Poma Hospital, Mantova, Italy. \\ Email: "bondimanuel@gmail.com
}

Received March 25 ${ }^{\text {th }}$ 2013; revised May $1^{\text {st }}, 2013$; accepted May $17^{\text {th }}, 2013$

Copyright (c 2013 Bruno Magnan et al. This is an open access article distributed under the Creative Commons Attribution License, which permits unrestricted use, distribution, and reproduction in any medium, provided the original work is properly cited.

\begin{abstract}
A minimally invasive surgical technique (MIS) is any procedure that could be less invasive than open surgery used for the same purpose. Though MIS often involves small incisions or percutaneous approaches, its main goal is to achieve good therapeutic results with the least damage to functional anatomic structures. Minimal invasiveness in orthopaedic forefoot surgery, including first ray and lesser toes, with its growth over the last two decade, showed many advantages and good outcomes with the aim to obtain fewer complications due to a contained approach, shorter surgical time and exposure, lesser post-operative risk of infection, lesser pain, hospitalization and post-operative recovery time, compared with traditional open approaches. This appears particularly true for what concerns hallux valgus surgical correction. MIS techniques have proven in the literature to be reliable, providing today comparable results with traditional open approaches.
\end{abstract}

Keywords: MIS; Forefoot; Hallux Valgus; Bunionette; Percutaneous Distal Osteotomy

\section{Introduction}

Minimally invasive techniques have became today one of the objectives in orthopaedic surgery.

Arthroscopy is the technique that best exemplifies the MIS concept in orthopaedic surgery as it replaced several traditional open procedures for the treatment of articular impingements, ligaments and tendon disorders and osteochondral lesions, using bone marrow stimulation techniques (drilling, microfractures), autologus chondrocyte implantation or using scaffolds with autogenic cells [13].

Concurrently this evolution of surgical techniques, a continuous improvement in the design and manufacturing of surgical MIS-dedicated instrumentations has been developed. The use of a $2.7 \mathrm{~mm}$ scope is preferable for arthroscopic procedures in the foot instead of the $4 \mathrm{~mm}$ scope used for the shoulder and the knee joints. It gives an excellent visual field and allows operation in limited spaces, such as the medial, lateral and posterior aspects of the ankle joint. Knifeblades, bone cutters, curettes, probes and forceps should be properly sized. Such instrumentation can be used in the endoscopic approach to

"Corresponding author. the plantar sheath and Achilles tendon or for endoscopic decompression of a Morton Neuroma.

In trauma surgery several MIS techniques have proved useful for fixation of fractures and other injuries [4]. For what concern foot and ankle trauma, in $1977 \mathrm{Ma}$ and Griffith [5] proposed a percutaneous repair for acute Achilles tendon tears, a technique that has became the treatment of choice in the majority of cases. Calcaneal fractures can now be managed using minimally invasive reduction and fixation techniques by external mini-fixators (Figures 1(a) and (b)) or using percutaneous cannulated screws [6-8], possibly allowing "augmentation" procedures with injectable polymers as bone substitutes [9]. For the treatment of fractures and dislocation of the Lisfranc joint and fractures of the base of the fifth metatarsal, Myerson [4] has shown that is possible to perform percutaneous fixations under fluoroscopic control.

For Haglund's calcaneal exostosis a minimally invasive technique, such as calcaneoplasty via endoscopic approach can be used [10,11]. Flat foot in childhood is nowadays currently treated with percutaneous lengthening of Achilles tendon and implantation of sinus tarsi spacers for the correction of the rearfoot Hyperpronation $[12,13]$. 


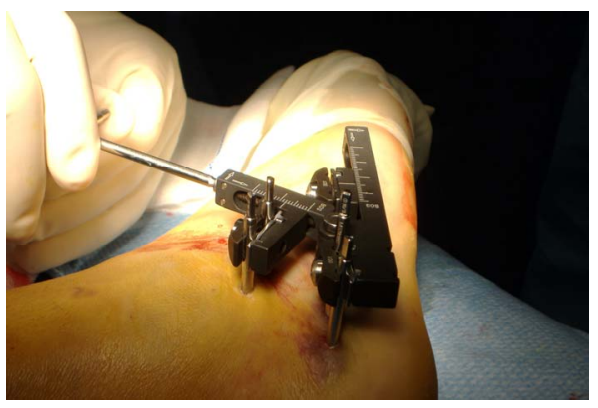

(a)

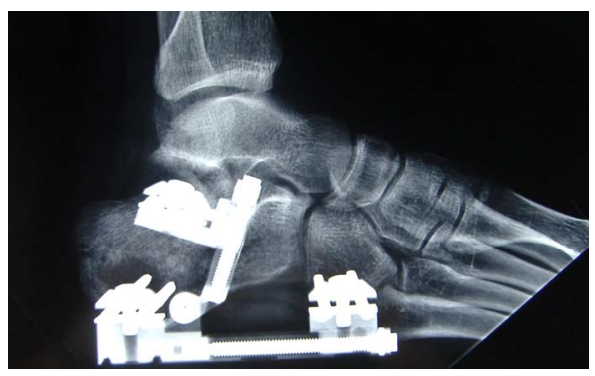

(b)

Figure 1. (a), (b) External mini-fixator for the minimally invasive reduction and fixation of the calcaneal fractures.

However, MIS represents still an "upper level” procedure compared to open surgery, with a long learning curve due to reduced surgical fields, difficult landmarks, needing anatomic knowledges of the structures usually met in traditional approaches.

\section{MIS for Forefoot}

In forefoot surgery MIS principles have been applied successfully and new applications are currently being studied.

Noteworthy in forefoot MIS represents today the last evolution in the treatment of the hallux valgus and associated deformities of the lesser rays [14-19], standardising the indications and the surgical techniques, clearly delineating the various procedural steps, corrective potentials, and with the proposal of the surgical algorithms based upon preoperative plannings. Lateral rays deformities to be treated in combination with Hallux valgus surgery and bilateral procedures should also be considered for MIS.

The development of MIS of the forefoot has been carried on by two major schools, the North American podiatry school, led by New and Isham [20-22], and the European orthopaedic school.

The North American podiatry experience since the 1980s is very important, adopting minimal surgical approaches and the use of micromotorised bone cutters for bony procedures.

At the end of the nineteenth century Reverdin, from the European school, suggested a correction of the hallux valgus by an isolated open distal osteotomy with a bony wedge removal at the neck of the first metatarsal. Later New and Isham in 1991 [21], proposed a MIS Reverdin-type osteotomy, with resection of a bony wedge at the medial aspect of the head of the first metatarsal combined with an Akin type osteotomy of the proximal phalanx and a percutaneous lateral release. This techniques has been adopted by some members of the European School in the late 1990s, especially by French and Spanish surgeons [23,24].

In 1993, Bosch et al. [20,22] applied the principles of percutaneous techniques to procedures for correction of hallux valgus, typical of the Wiener School. He suggested a distal osteotomy of the first metatarsal as described by Lamprect and Kramer [25], a modified uniplanar procedure attributed to Hohmann in 1921 [26]; using a displacer probe, the head is moved laterally and fixation is achieved with a K-wire in a parosteal position in the distal portion of the osteotomy, and intramedullary in the proximal part, fully complying with the principles of the original open technique.

In 1997 Magnan et al. [14] suggested the Percutaneous Distal Osteotomy (PDO), and later in 2000 Giannini et al. proposed the SERI technique [17], as well as Maffulli in 2005 [27-29], all following the footsteps of the principles of Homan, Lamprect and Kramer, and Bosch.

Many metatarsal osteotomies which in past where proposed as isolated bone procedure, can now be effectively performed with a minimally invasive technique whenever an adequate stabilization is obtained [14,20,22,3033]. At the same time surgical procedure on soft tissue, such as tenotomy, joint release, cheilectomy and capsular retensioning, have became less important in the surgical treatment of hallux valgus, not significantly affecting therapeutic results when associated with an osteotomy, but increasing surgical exposure, as well as the risk of complications.

In severe hallux valgus deformity De Lavigne et al. [34] have recently proposed a percutaneous double osteotomy of the first metatarsal with proximal closing wedge and distal chevron osteotomy.

Distal osteotomies of the lesser metatarsal bone through MIS are now being undertaken [23]. Other procedures, such as proximal osteotomies of the first metatarsal [35], which require extensive and isolated procedures on soft tissues, are not easily suitable for MIS.

Surgeons who are going to adopt minimally invasive methods need to have a thorough knowledge of the districts where the procedure will take place, they must be aware of the structures with which they might interfere, often without a direct view, since possible damages might occur if neurovascular bundles are involved. Since most percutaneous surgical procedures are performed through minimal incisions, the approaches must be rig- 
idly standardized to allow clear vision of the maneuvers being performed. In many cases, great help can be given by fluoroscopy, although its use should be minimized. Moreover, specific instruments have been developed for the surgical correction of hallux valgus and for additional procedures on the lesser rays.

\section{MIS Techniques in Forefoot}

\subsection{Percutaneus Distal Osteotomy of the First Metatarsal (Hallux Valgus)}

The percutaneous distal osteotomy has evolved from the traditional open techniques for the treatment of hallux valgus that depend on stabilization with a Kirschner wire and was standardized by Bösch et al. It was introduced in Italy in 1997 by Magnan et al. [14,16,19] and it is considered to be a "third-generation" procedure in that it represents the minimally invasive evolution of traditional osteotomies of the first metatarsal.

It consists of an extra-articular, distal osteotomy of the first metatarsal with a wide lateral displacement and a medial tilt of the capital fragment then "stabilized and not fixed" [14] with a K-wire inserted in a distal-proximal direction. Such a displacement of the head enables correction of the varus deviation of the first metatarsal according to the general biomechanic principles of "distal" osteotomies of the first metatarsal. This uniplanar osteotomy allows a multiplanar correction since the capital fragment can be displaced laterally, tilted in the axial plane for the correction of the distal metatarsal articular angle (DMAA), plantarised for the recovery of weight-bearing ability and rotated on frontal plane for correction of pronation.

Assessment of the combined lesser rays deformities that are to be treated simultaneously should also be performed.

Indications for performing a percutaneous distal osteotomy are the same as those of a distal osteotomy with an open technique and lateral soft-tissue release, with the difference that an intermetatarsal angle of up to $20^{\circ}$ is still suitable for the procedure. This is due to the fact that the large lateral displacement allowed up to $90 \%$ of the transverse diameter of the first metatarsal increases the corrective potential, as opposed to a range between 30\% and 50\% commonly obtained with distal osteotomies and internal fixation.

The only real contraindication to this procedure is an hallux rigidus, where the presence of severe degenerative changes indicates the need for an open procedure for a cheilectomy or a fusion.

Operation can be performed bilaterally with an "ankle block" anesthesia $[36,37]$ and is facilitated by the use of fluoroscopy to monitor some surgical steps.

The first approach is carried out approximately 2 to 3 $\mathrm{mm}$ from the medial corner of the nail of the great toe with a K-wire mounted on the handset in distal-proximal direction still in the parosteal position.

The site of the osteotomy is carried out at the distal metaphysis of the first metatarsal on the medial side. The periosteum around the osteotomy site is detached first, with use of small scissors inserted through the percutaneous approach dorsally and then plantarly. In this way, the structures surrounding the metatarsal shaft can be kept far from the bone cutter. The osteotomy is then performed through the subcapital region of the first metatarsal with use of a thin 2.33-mm-diameter micromotorized Lindemann bone cutter (Aesculap, Tuttlingen, Germany) (Figures 2(a) and (b)). The cut is made in a single plane, perpendicular to the axis of the shaft of the first metatarsal in the sagittal plane. The mediolateral obliquity of the osteotomy in the frontal plane makes it possible to lengthen or shorten the metatarsal with lateral displacement of the head fragment (Figure 2(c)). The osteotomy enables the surgeon to achieve an appreciable degree of lateral displacement and slight plantar displacement of the hallux and the metatarsal head. Furthermore, the metatarsal head can be rotated in the axial plane to correct the rotational components of the deformity. The percutaneous displacement of the first metatarsal head is best achieved with the use of the Bösch device, which is a bent grooved probe. The distal edge of the device is smooth and is bent over a distance of about 4 cm (Tecres, Verona, Italy) (Figures 2(d) and (e)). The osteotomy site is then stabilized by means of a 2-mm Kirschner wire, which is inserted from distal to proximal in a parosteal position in relation to the hallux and the head of the first metatarsal and then into the medullary canal of the first metatarsal; it is firmly driven as far as the base of the first metatarsal in order to improve stabilization (Figure 2(f)).

The wire is kept in that site for four weeks. No associated soft-tissue procedures are performed. In particular, lateral release with dissection of the soft tissues is never done.

Postoperatively, functional taping is of fundamental importance. The tape, which is kept in situ for six weeks and is replaced every week, is coupled to a plantar "kidney-shaped" pad, with its concavity surrounding the plantar aspect of the head of the first metatarsal in order to reduce the local weight-bearing pressure beneath the capital fragment and prevent dorsiflexion of the capital fragment. The tape maintains a slight hypercorrection of the hallux in order to counter any recurrence of pronation. Patients are allowed to walk on the day after the operation with the use of appropriate postoperative footwear with a flat rigid sole. After the tape is removed, patients are encouraged to exercise the first metatarsophalangeal joint, taking particular care to obtain full dorsiflexion 


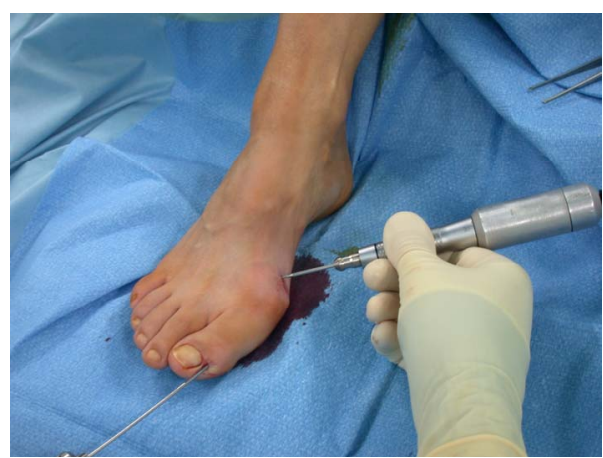

(a)

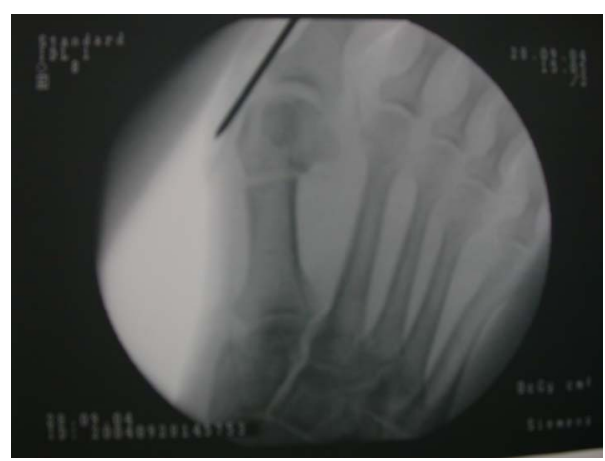

(c)

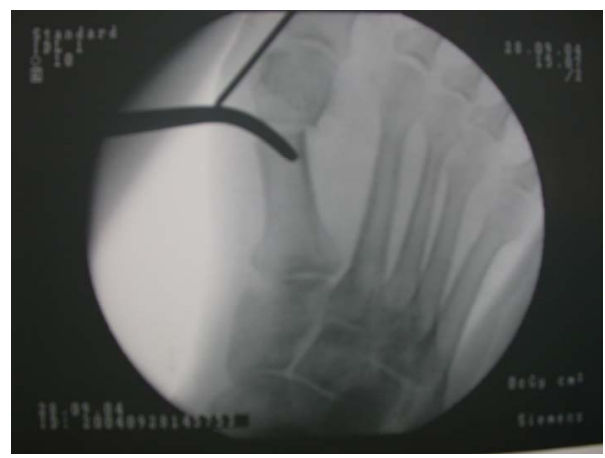

(e)

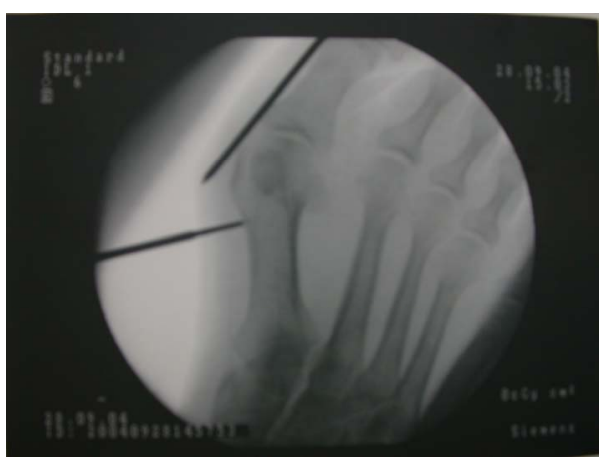

(b)

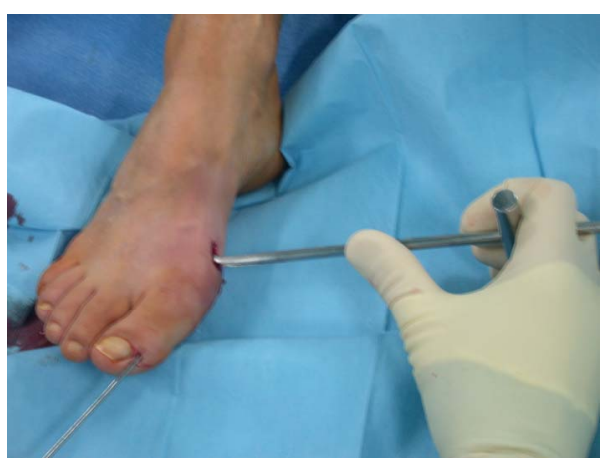

(d)

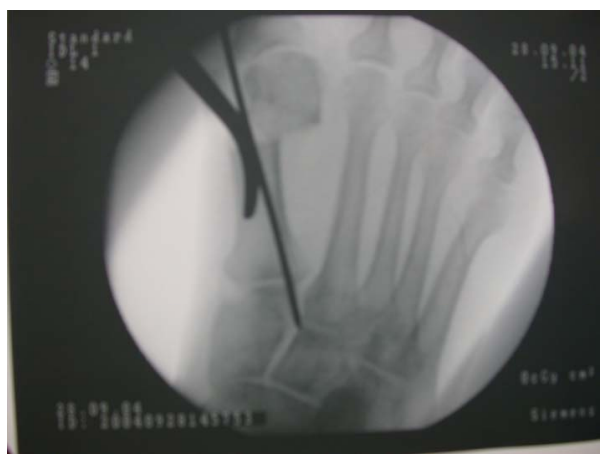

(f)

Figure 2. (a), (b) The K-wire is driven manually in a distal to proximal from 2 - $3 \mathrm{~mm}$ from the lateral nail bed. Checked with fluoroscopy the correct location of osteotomy, it is then performed through the subcapital region of the first metatarsal with use of a thin 2.33-mm-diameter micromotorized Lindemann bone cutter. The cutting is carried out on a single plane; (c) The osteotomy is carried out using multiple mid-lateral perforations keeping obliquity that conserves the segment geometry. The completeness of the osteotomy is controlled fluoroscopy; (d), (e) The displacer instrument is inserted percutaneously into the proximal stump of the osteotomy; (f) The osteotomy is stabilized by the K-wire progression in a proximal direction within the first metatarsal diaphyseal.

within four to six weeks.

The PDO yields good results in almost $90 \%$ of patients [14,16,19] (Figures 3(a)-(c)). The results appear to be comparable with those reported following traditional open techniques [38-40] and the technique has all of the advantages of a minimally invasive procedure [41].

Controversial results have been reported in 2007 by Kadakia et al. [42] using two K-wires to stabilize a first metatarsal osteotomy performed at a more diaphyseal site, with a high rate of complications due to loss of correction and recurrence after removal of the intramedullary
K-wire, as well as dorsal elevation of the capital fragment, but these authors refer to a modified procedure in most of surgical steps, which cannot be considered similar neither to a PDO not to a SERI $[14,17]$.

\subsection{Percutaneous Arthrodesis of Interphalangeal Joints of the Lesser Rays}

A minimally invasive percutaneous procedure can be used to perform a stable arthrodesis of the proximal or distal interphalangeal joints of the lateral rays [19]. The 


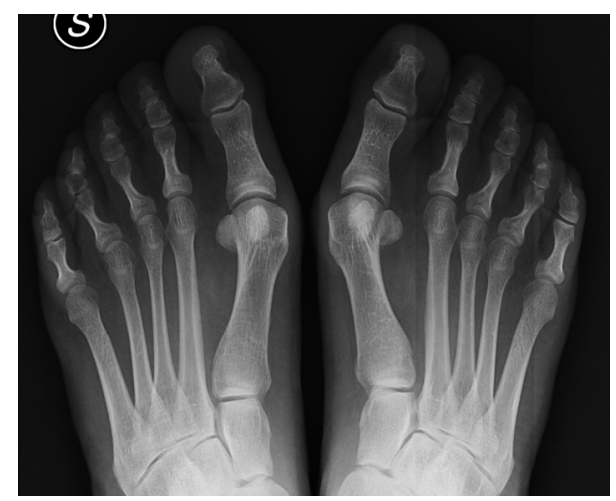

(a)

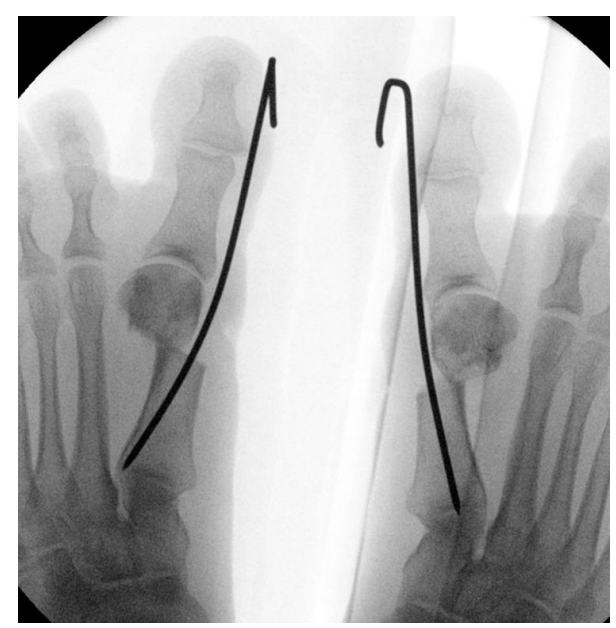

(b)

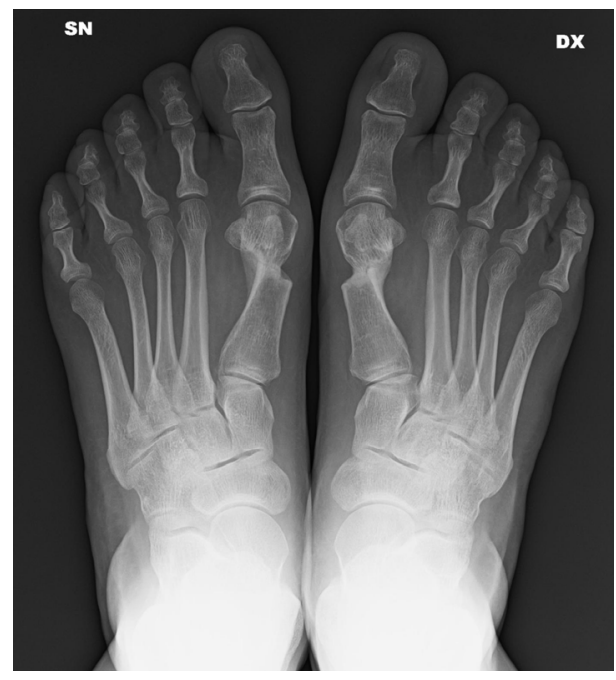

(c)

Figure 3. (a) Patient of 55 years old with bilateral hallux valgus. PDO bilateral surgery performed; (b), (c) The postoperative radiograph and a 3-month follow-up.

procedure has the same indications of open traditional techniques and avoids the need to perform lengthening, tenodesis or transposition of the tendons, particularly with clawed or hammer toe.
The approach is dorsal, paratendinous at the involved joint. A 2 - 3-mm. arthrotomy is performed and a micromotorised Lindemann bone cutter is inserted into the joint space. The joint surfaces are then freshened until the deformity is mobilized and corrected. Fixation of the arthrodesis is performed using a 1.2 to $1.5 \mathrm{~mm}$ intramedullary K-wire, which should not go past the base of the proximal phalanx inserted in a distal-proximal direction from the tip of the toe.

The results are comparable with traditional techniques [43], with a reduction in operating time and risk of complications.

\subsection{Percutaneus Distal Osteotomy of the Fifth Metatarsal (Bunionette)}

Distal osteotomy of the fifth metatarsal is indicated in the surgical treatment of bunionette and varus deformity of the fifth toe in patients with a valgus deviation of the fifth metatarsal [18]. There are many different techniques used to correct deformity of the fifth metatarsal, including soft-tissue procedures, metatarsal osteotomies, or prosthetic implants. Among the several procedures described, a minimally invasive or percutaneous distal osteotomy of the fifth metatarsal has the potential to reduce complications due to limited surgical exposure $[15,18]$.

Surgery is performed with use of ankle block anesthesia. The percutaneous approach begins with the insertion of a 2-mm Kirschner wire in a parosteal position, starting from the upper-outer corner of the nail bed of the fifth toe. The wire is driven from distal to proximal so that it lies alongside the lateral side. Then the osteotomy is then performed through the subcapital region on the lateral side of the distal metaphysis of the fifth metatarsal with the Lindemann bone cutter. The cut is made in a single plane, perpendicular to the axis of the shaft of the fifth metatarsal in the sagittal plane or with a slight mediolateral obliquity, in order to prevent a shortening of the metatarsal and to achieve medial displacement of the head fragment. Displacement of the fifth metatarsal head is best achieved with use of a bent, grooved probe. No associated soft-tissue procedures are performed. The osteotomy site is then stabilized by means of the 2-mm Kirschner wire, which is driven into the medullary canal of the fifth metatarsal as far as its base. To maintain rotation and correction post-operatively, a taping is applied with a plantar pad in order to reduce weight-bearing pressure on the capital fragment (Figures 4(a)-(c)).

Beginning on the day after the operation, the patient is allowed to walk without the aid of crutches but with the use of a post-operative shoe. The taping is maintained for six weeks, and the Kirschner wire is removed at four weeks after surgery.

The percutaneous distal osteotomy, performed through a minimally invasive percutaneous approach without soft- 


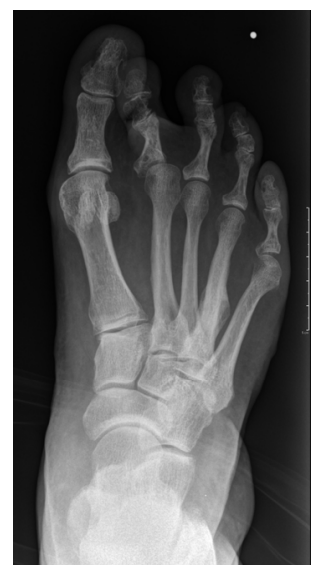

(a)

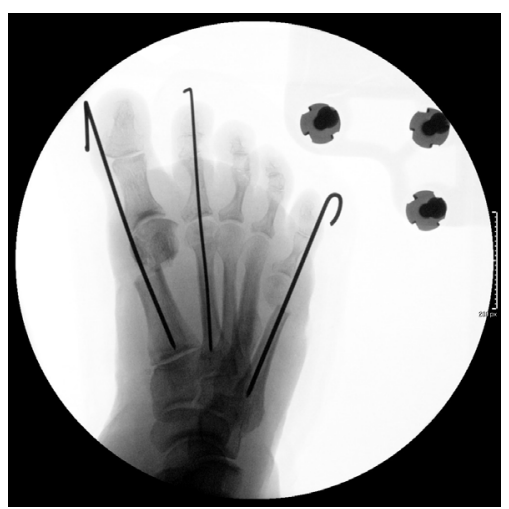

(b)

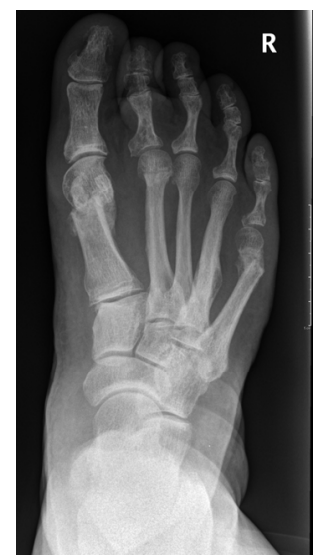

(c)

Figure 4. (a) Patient of 58 years old with hallux valgus, bunionette and varus deformity of the fifth toe. PDO surgery of the $1^{\text {st }}$ metatarsal performed and Percutaneus Distal Osteotomy of the fifth metatarsal (bunionette); (b), (c) The post-operative radiograph and a 3-month follow-up.

tissue procedures, enables the surgeon to achieve a consistently good correction of the fifth metatarsal deformity with comparable results to those reported with traditional open distal osteotomies [44]. We can therefore consider the percutaneous distal osteotomy of the fifth metatarsal to be a safe and reliable technique that also offers the potential benefits of a minimally invasive procedure, including a very short operative time and early return to walking.

\subsection{Percutaneous Osteotomy of Lesser Metatarsal Bones}

The general principle in MIS distal osteotomies of lesser metatarsal bone, as described by De Prado et al. [24], is to perform a complete, oblique extra-articular osteotomy of the metatarsal neck using a Lindemann bone cutter, bent at a 45 degree inclination on the axis of the metatarsal bone, from distal-dorsal to plantar-proximal, in order to allow the capital fragment to slide obliquely in the axial plane. This osteotomy is indicated in painful lesser metatarso-phalangeal diseases with a grade 1 and 2 joint instability according to Coughlin's classification [45]. The consolidation position is determined by weightbearing and occurs at a more proximal site, thus allowing the shortening and sometimes dorsiflexion of the capital fragment. The approach should be from the lateral side. The procedure may be combined with osteotomies of proximal phalanxes through a plantar approach as originally described by Piquè-Vidal and De Prado [24], in case of fixed dislocation of the metatarso-phalangeal joint, even if an open distal osteotomy of lateral metatarsal bones according to Wolf-Jimenez-De Orio [46] should be considered most appropriate with a grade 3 metatarso-phalangeal instability according to Coughlin classification corresponding to a true dorsal dislocation of the joint [45] (Figures 5(a)-(d)).

\subsection{Percutaneous Alcoholization for Interdigital Neuritis (Morton's Neuroma)}

Symptomatic treatment of Civinini-Morton syndrome may be performed directly on the involved nervous branch using orthotics, local drug injections or surgery.

New techniques for a minimally invasive approaches have been described [47-49].

Barret et al. [47] have developed an endoscopic approach to the surgical treatment of Morton's neuroma. This technique is based on the endoscopic decompression of the intermetatarsal nerve entrapment.

Alcoholization with phenol or ethanol by a percutaneous approach has the aim to induce a permanent chemical neurolysis, obtaining remission of the neuritic painful symptoms [48].

By a dorsal intermetatarsal approach, the nervous branch is localized proximally to the metatarsal heads by an electrostimulator or with the aid of sonography; using an electrode-needle of $2 \mathrm{ml}$. amount of 5 percent concentration phenol or 90 percent concentration ethanol is injected around the involved nerve. The procedure is safe and can be repeated up to three times monthly in case of 


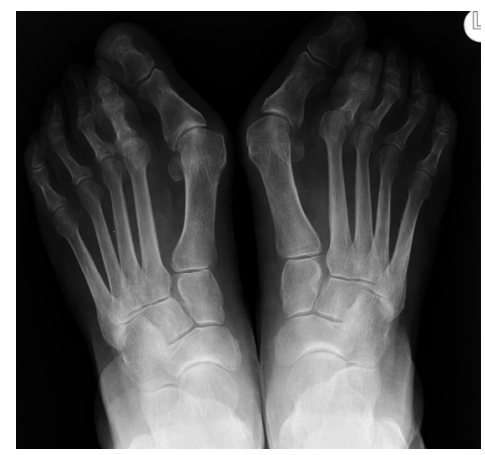

(a)

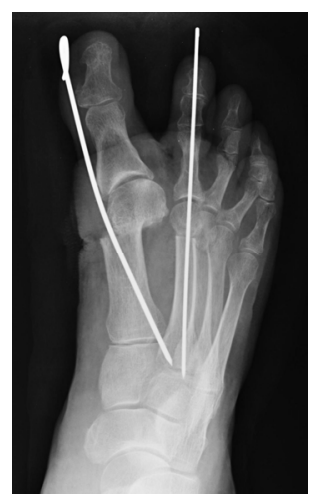

(b)

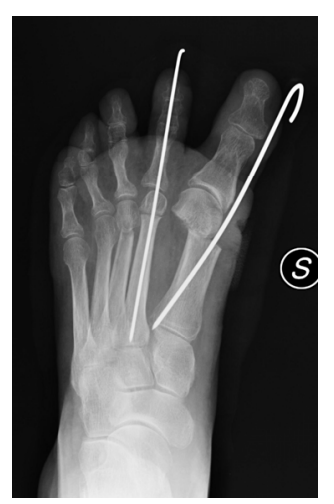

(c)

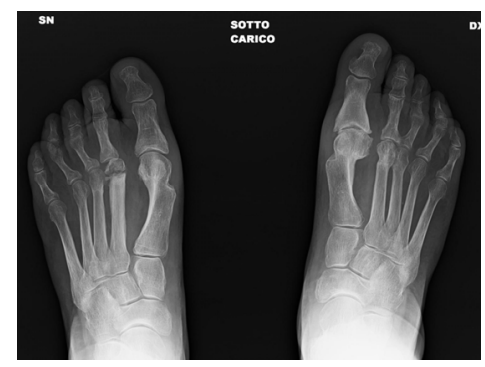

(d)

Figure 5. (a) Patient of 68 years old with bilateral hallux valgus and a bilateral grade 3 of the $2^{\text {nd }}$ metatarso-phalangeal instability according to Coughlin classification. PDO bilateral surgery of the $1^{\text {st }}$ metatarsal performed and an open distal osteotomy of $2^{\text {nd }}$ metatarsal bones according to Wolf-Jimenez-De Orio; (b)-(d) The post-operative radiograph and a 3-month follow-up. a partial effect.

The results of percutaneous alcoholization of the common interdigital nerve by phenol injection proved to be effective in about $80 \%$ of cases. This approach showed considerable better results when compared with those reported in the literature with conservative treatment or local steroid injection, and even comparable with those obtained with surgical nevrectomy in absence of complications related to surgical approach.

\section{Conclusions}

Among many different surgical treatments proposed for forefoot pathologies, several minimal invasive procedures are currently became a common choice.

MIS includes complex upper level techniques with a rather long learning curve due to reduced surgical fields, difficult landmarks, needing exact anatomic knowledge of the structures usually which meet in traditional approaches. Consequently, high technology, small and dedicated instruments have been developed but, on the other hand, the use of fluoroscopy is often necessary with risk of more exposure to radiations.

New MIS techniques are reliable, providing today comparable results than traditional open approaches. Operative, hospitalization and recovering times as well as costs can be reduced [28] due to a lesser surgical exposure and a contained deep soft tissue dissection.

MIS and percutaneous surgery of forefoot is to be considered still a "work in progress" requiring unceasing research, continuous critical monitoring of the outcomes, selection of the most suitable techniques, and development of new instrumentation.

Nevertheless, MIS belongs rightfully to current forefoot surgery and in the near future will allow the replacement of procedures that have proven less effective, most dangerous and then obsolete.

\section{REFERENCES}

[1] S. Giannini and F. Vannini, "Operative Traeatment of Ostheochondral Lesions of the Talar Dome: Current Concepts Review,” Foot \& Ankle International, Vol. 25, No. 3, 2004, pp. 168-175.

[2] B. Magnan, E. Samaila, M. Bondi, E. Vecchini, G. M. Micheloni and P. Bartolozzi, "Three-Dimensional MatrixInduced Autologous Chondrocytes Implantation for Osteochondral Lesions ofthe Talus: Midterm Results,” Advances in Orthopedics, Vol. 2012, 2012, Article ID: 942174. doi:10.1155/2012/942174

[3] A. Bertelli, R. Bertino, A. Graziano and M. Cossavella, "L’Artroscopia di Caviglia Associata Alla Ricostruzione Legamentosa Nelle Instabilità,” In: M. Bardelli, M. Guelfi and F. Ceccarelli, Eds., Artroscopia Della Caviglia e del Piede, TIMEO, Bologna, 2006, pp. 129-142.

[4] M. S. Myerson, “The Diagnosis and Treatment of Injury 
to the Tarso-Metatarsal Joint Complex," The Bone \& Joint Journal, Vol. 81, No. 5, 1999, pp. 756-763. doi:10.1302/0301-620X.81B5.10369

[5] W. C. Ma and T. G. Griffith, "Percutaneous Repair of Acute Closed Ruptured Achilles Tendon,” Clinical Orthopaedics and Related Research, No. 128, 1977, pp. 247-255.

[6] F. J. Cotton and L. T. Wilson, "Fractures of the Oscalcis," The Boston Medical and Surgical Journal, Vol. 159, 1908, pp. 559-565. doi:10.1056/NEJM190810291591801

[7] P. Rajkumar and A. A. Henderson, "Surgical Treatment of Dispiaced Intra-Articular Fractures of the Calcis,” Foot and Ankle Surgery, Vol. 9, No. 1, 2003, pp. 3-6. doi:10.1016/S1268-7731(03)00010-9

[8] J. Kenwright, "Fractures of the Calcaneum," The Bone \& Joint Journal, Vol. 75, No. 2, 1993, pp. 176-177.

[9] B. Magnan, R. Bortolazzi, A. Marangon, M. Marino, C. Dall'Oca and P. Bartolozzi, "External Fixation for Displaced Intra-Articular Fractures of the Calcaneum," The Bone \& Joint Journal, Vol. 88, No. 11, 2006, pp. 14741479. doi:10.1302/0301-620X.88B11.17759

[10] C. N. Van Dijk, G. E. Van Dijk, P. E. Scholten and N. P. Kort, "Endoscopic Calcaneoplasty," The American Journal of Sports Medicine, Vol. 29, No. 2, 2001, pp. 185-189.

[11] M. Guelfi, E. Abello and F. Priano, “L'impiego Dell'Endoscopia Negli Spazi Extra-Articolari Dell'Arto Inferiore," Rivista Italiana di Biologia e Medicina, Vol. 1-2, Suppl. 1, 2002, pp. 231-234.

[12] B. Magnan, C. Balgrighi, D. Papadia and P. Bartolozzi, "Il Piede Piatto: Tecniche Chirurgiche a Confronto. Risultati del Gruppo di Studio Sull'Endortesi Retrograda per il Calcaneo-Stop,” Italian j Pediatr Orthop, Vol. 13, Suppl. 1, 1997, pp. 211-216.

[13] S. Giannini, F. Ceccarelli, F. Vannini and E. Baldi, “Operative Treatment of Flat-Foot with Talocalcaneal Coalition," Clinical Orthopaedics and Related Research, Vol. 411, No. , 2003, pp. 178-187. doi:10.1097/01.blo.0000069897.31220.7a

[14] B. Magnan, L. Pezzè, N. Rossi and P. Bartolozzi, "Percutaneous Distal Metatarsal Osteotomy for Correction of Hallux Valgus,” The Journal of Bone \& Joint Surgery, Vol. 87, No. 6, 2005, pp. 1191-1199. doi:10.2106/JBJS.D.02280

[15] S. Giannini, C. Faldini, F. Vannini F, V. Digennaro, R. Bevoni and D. Luciani, "The Minimally Invasive Osteotomy 'S.E.R.I.' (Simple, Effective, Rapid, Inexpensive) for Correction of Bunionette Deformity," Foot \& Ankle International, Vol. 29, No. 23, 2008, pp. 282-286. doi:10.3113/FAI.2008.0282

[16] B. Magnan B, R. Bortolazzi, E. Samaila, L. Pezzè, N. Rossi and P. Bortolozzi, "Percutaneous Distal Metatarsal Osteotomy for Correction of Hallux Valgus. Surgical Technique,” The Journal of Bone \& Joint Surgery, Vol. 88A, Suppl. 1, 2006, pp. 135-148.

[17] S. Giannini, F. Ceccarelli, R. Bevoni and F. Vannini, "Hallux Valgus Surgery: The Minimally Invasive Bunion Correction (S.E.R.I.),” In: Lippincott, Williams and Wilkins, Eds., Techniques in Foot Ankle Surgery, Philadel- phia, 2003, Vol. 2.

[18] B. Magnan, E. M. Samaila, M. Merlini, M. Bondi, S. Mezzari and P. Bartolozzi, "Percutaneous Distal Osteotomy of the Fifth Metatarsal for Correction of Bunionette,” The Journal of Bone \& Joint Surgery, Vol. 93, No. 22, 2011, pp. 2116-2122. doi:10.2106/JBJS.J.01177

[19] B. Magnan, A. Bragantini., S. Fieschi, C. Balgrighi and P. Bartolozzi, "Le Deformità Post Traumatiche Delle Dita Laterali,” In: S. Giannini, S. Martinelli and A. Volpe, Eds., La Patologia Delle Dita Esterne. Progressi in Medicina e Chirurgia del Piede, Aulo Gaggi, Bologna, 1999, pp. 51-58.

[20] P. Bosch, H. Markowski and V. Rannicher, "Technik und Erste Ergebnisse der Subkutanen Distalen Metatarsale, I Osteotomie,” Orthopaedische Praxis, Vol. 26, 1990, pp. 51-56.

[21] S. A. Isham, “The Reverdin-Isham Procedure for Correction of Hallux Abductovalgus: A Distal Metatarsal Procedure,” Clinics in Podiatric Medicine and Surgery, 1991, pp. 881-894.

[22] P. Bösch, S. Wanke and R. Legenstein, "Hallux Valgus Correction by the Method of Bösch: A New Technique with a Seven-to-Ten-Year Follow-Up," Foot and Ankle Clinics, Vol. 5, No. 3, 2000, pp. 485-498.

[23] O. Laffenetre, C. Cermolacce and J. Y. Coillard, “Traitement Chirurgical de l'Hallux Valgus par Technique Percutanèe,” In: B. Valtin, Ed., Chirurgie de l'Avantpied, Sociètè Francaise de Orthopèdique et Traumatologique, Elsevier, 2005.

[24] M. De Prado, P. L. Ripoll and P. Golanò, “Cirurgìa Percutanea del pie,” Masson, Barcelona, 2004.

[25] J. Kramer, "Die Kramer-Osteotomie zur Behandlung des Hallux Valgus und des Digitus Quintus Varus," Operative Orthopädie und Traumatologie, Vol. 2, No. 1, 1990, pp. 29-38. doi:10.1007/BF02512334

[26] G. Hohmann, "Symptomatische oder Physiologische Behandlung des Hallux Valgus," Munchener Medizinische Wochenschrift, Vol. 68, 1921, pp. 1942-1945.

[27] N. Maffulli, V. Denaro and M. Loppini, "Bosch Osteotomy,” Foot \& Ankle International, Vol. 33, No. 9, 2012, pp. 808-809.

[28] N. Maffulli, U. G. Longo, A. Marinozzi and V. Denaro, "Hallux Valgus: Effectiveness and Safety of Minimally Invasive Surgery. A Systematic Review,'” British Medical Bulletin, Vol. 97, No. 1, 2011, pp. 149-167. doi:10.1093/bmb/ldq027

[29] N. Maffulli, F. Oliva, C. Coppola and D. Miller, "Minimally Invasive Hallux Valgus Correction: A Technical Note and a Feasibility Study," Journal of Surgical Orthopaedic Advances, Vol. 14, No. 4, 2005, pp. 193-198.

[30] J. Reverdin, "De la Deviation en de Hors du gros Cortei (Hallux Valgus, Vulg, 'Oignon' 'Bunions' 'Ballen') e de son Traitment Chirurgical,” Trans-Pacific Partnership Negotiations and Issues for Congress, Vol. 2, 1881, pp. 408-412.

[31] G. Hohmann, "Symptomatiche oder Physiologische Behandlung des Hallux Valgus," Munchener Medizinische Wochenschrift, Vol. 68, 1921, pp. 1042-1045. 
[32] D. W. Austin and E. O. Leventen, “A New Osteotomy for Hallux Valgus: A Horizontally Directed 'V' Displacement Osteotomy of the Metatarsal Head for Hallux Valgus and Primus Varus," Clinical Orthopaedics and Related Research, Vol. 157, No. 6, 1981, pp. 25-30.

[33] O. F. Akin, "The of Hallux Valgus: A New Operative Procedure and Its Results,” Medical Sentinel, Vol. 33, 1925, pp. 678-679.

[34] C. De Lavigne, Q. Rasmont and B. Hoang, "Percutaneous Double Metatarsal Osteotomy for Correction of Severe Hallux Valgus Deformity,” Acta Orthopaedica Belgica, Vol. 77, No. 4, 2011, pp. 516-521.

[35] J. A. Ruch and A. S. Banks, "Proximal Osteotomy of the First Metatarsal in the Correction of Hallux AbductoValgus,” In: E. Dalton McGlamry, Ed., Comprehensive Textbook of Foot Surgery, Williams \& Wilkins, Baltimore, 1987, Vol. 1.

[36] T. E. Reilley and M. A. Gerhardt, "Anesthesia for Foot and Ankle Surgery," Clinics in Podiatric Medicine and Surgery, Vol. 19, No. 1, 2002, pp. 125-147. doi:10.1016/S0891-8422(03)00084-3

[37] T. Leemrijse, B. Valtin and J. L. Besse, "Conventional, Mini-Invasive or Percutaneous Surgery? Uni- or Bilateral? Hospitalisation or One-Day Surgery?” Hallux Valgus Surgery in 2005," Revue de Chirurgie Orthopédique et Réparatrice de l'Appareil Moteur, Vol. 92, No. 2, 2008, pp. 111-127. doi:10.1016/i.rco.2007.04.006

[38] H. J. Trnka, A. Zembsch, M. E. Easlev, M. Salzer, P. Ritschl and M. S. Myerson, "The Chevron Osteotomy for Correction of Hallux Valgus: Comparison of findings after Two and Five Years of Follow-Up," The Journal of Bone and Joint Surgery. American Volume, Vol. 82-A, No. 10, 2000, pp. 1373-1378.

[39] R. A. Mann, S. Rudicel and S. C. Graves, "Repair of Hallux Valgus with a Distal Soft-Tissue Procedure and Proximal Metatarsal Osteotomy: A Long Term Follow-Up," The Journal of Bone and Joint Surgery. American Volume, Vol. 74, No. 1, 1992, pp. 124-129.

[40] T. Bauer, C. de Lavigne, D. Biau, M. De Prado, S. Isham and O. Laffenétre, "Percutaneous Hallux Valgus Surgery: A Prospective Multicenter Study of 189 Cases,” Orthopedic Clinics of North America, Vol. 40, No. 4, 2009, pp. 505-514. doi:10.1016/j.ocl.2009.05.002
[41] Y. A. Radwan and A. M. Mansour, "Percutaneous Distal Metatarsal Osteotomy versus Distal Chevron Osteotomy for Correction of Mild-to-Moderate Hallux Valgus Deformity," Archives of Orthopaedic and Trauma Surgery, Vol. 132, No. 11, 2012, pp. 1539-1546. doi:10.1007/s00402-012-1585-5

[42] A. R. Kadakia, J. P. Smerek and M. S. Myerson, "Radiographic Results after Percutaneous Distal Metatarsal Osteotomy for Correction of Hallux Valgus Deformity," Foot \& Ankle International, Vol. 28, No. 3, 2007, pp. 355-360. doi:10.3113/FAI.2007.0355

[43] M. L. Boyer and J. K. DeOrio, "Metatarsal Neck Osteotomy with Proximal Interphalangeal Joint Resection Fixed with a Single Temporary Pin,” Foot \& Ankle International, Vol. 25, No. 3, 2004, pp. 144-148.

[44] M. J. Coughlin, “Treatment of Bunionette Deformity with Longitudinal Diaphyseal Osteotomy with Distal Soft Tissue Repair,” Foot \& Ankle International, Vol. 11, No. 4, 1991, pp. 195-203. doi:10.1177/107110079101100402

[45] M. J. Coughlin, R. A. Mann and C. L. Saltzman, "Surgery of the Foot and Ankle," 8th Edition, Mosby-Elsevier, Philadelphia, 2007.

[46] A. L. Jimenez, "Oblique V Lesser Metatarsal Osteotomy,” In: B. S. Schlefman, Ed., Doctors Hospital Podiatric Education and Research Institute Twelfth Surgical Seminar Syllabus, Doctors Hospital Podiatry Institute, Tucker, 1983.

[47] S. L. Barret and T. T. Pignetti, "Endoscopic Decompression for Intermetatarsal Nerve Entrapment-The EDIN Technique: Preliminary Study with Cadaveric Specimens; Early Clinical Results,” The Journal of Foot and Ankle Surgery, Vol. 33, No. 3, 1994, pp. 503-508.

[48] B. Magnan, A. Marangon, A. Frigo and P. Bartolozzi, "Local Phenol Injection in the Treatment of Interdigital Neuritis of the Foot (Morton's Neuroma)," La Chirurgia Degli Organi Di Movimento, Vol. 90, No. 4, 2005, pp. 371-377.

[49] R. E. Musson, J. S. Sawhney, L. Lamb, A. Wilkinson and H. Obaid, "Ultrasound Guided Alcohol Ablation of Morton's Neuroma,” Foot \& Ankle International, Vol. 33, No. 3, 2012, pp. 196-201. doi:10.3113/FAI.2012.0196 